\title{
Heterogeneous Electrochemical Immunoassay of Hippuric Acid on the Electrodeposited Organic Films
}

\author{
Young-Bong Choi ${ }^{1}$, Nam-Hyuk Kim ${ }^{1}$, Seung-Hoi Kim ${ }^{1}$, Gun-Sik Tae ${ }^{2}$ and Hyug-Han Kim ${ }^{1, *}$ \\ 1 Department of chemistry, College of Natural Science, Dankook University, Anseo-Dong, \\ Cheonan 330-714, Korea; E-Mails: chem0404@dankook.ac.kr (Y.-B.C.); \\ albireo0827@naver.com (N.-H.K.); kimsemail@dankook.ac.kr (S.-H.K.) \\ 2 Department of biology, College of Natural Science, Dankook University, Anseo-Dong, \\ Cheonan 330-714, Korea; E-Mail: gtae@dankook.ac.kr \\ * Author to whom correspondence should be addressed; E-Mail: hankim@dankook.ac.kr; \\ Tel.: +82-41-550-3435; Fax: +82-41-559-7860.
}

External Editor: Alexander Star

Received: 24 July 2014; in revised form: 5 September 2014 / Accepted: 25 September 2014 / Published: 13 October 2014

\begin{abstract}
By directly coordinating hippuric acid (HA) to the ferrate (Fe) as an electron transfer mediator, we synthesized a Fe-HA complex, which shows a good electrochemical signal and thus enables the electrochemical immunoanalysis for HA. We electrodeposited organic films containing imidazole groups on the electrode surface and then bonded $\mathrm{Ni}$ ion (positive charge) to induce immobilization of Fe-HA (negative charge) through the electrostatic interaction. The heterogeneous competitive immunoassay system relies on the interaction between immobilized Fe-HA antigen conjugate and free HA antigen to its antibody (anti-HA). The electric signal becomes weaker due to the hindered electron transfer reaction when a large-sized HA antibody is bound onto the Fe-HA. However, in the presence of HA, the electric signal increases because free HA competitively reacts with the HA antibody prior to actual reaction and thus prevents the HA antibody from interacting with Fe-HA at the electrode surface. This competition reaction enabled an electrochemical quantitative analysis of HA concentration with a detection limit of $0.5 \mu \mathrm{g} \mathrm{mL}{ }^{-1}$, and thus allowed us to develop a simple and rapid electrochemical immunosensor.
\end{abstract}

Keywords: hippuric acid; toluene; electrochemical immunosensor 


\section{Introduction}

Toluene is a broadly applied compound in chemical synthesis, in paints, in detergents, in adhesives, and in the petroleum industry. Those who are exposed to toluene for a long time have been found to suffer from anatomical changes in the brain. Simple monitoring of exposure to toluene is very important in occupational health care. Hippuric acid (HA), which is a major component of toluene metabolites, is a chemical compound with a molecular weight of $178.17 \mathrm{Da}$. Urinary HA concentration is widely used as a "target compound of toluene exposure" [1-3] and is measured by radioimmunoassay, enzyme linked immunosorbent assay (ELISA), UV-Visible spectroscopy, gas chromatography, and high performance liquid chromatography (HPLC). Among of these methods, HPLC-based analysis currently represents the most popular technique due to its simplicity and the fact that it does not involve radioactivity [4-7]. However, it is unsuitable for simultaneously analyzing a large number of samples and requires expensive equipment and trained technicians. To allow the measurement of many samples simultaneously, the ELISA technique was developed and has been used. However, it involves the use of expensive chemicals, such as enzymes and staining reagents, and equipment, such as an ELISA washer and an ELISA reader, as well as highly skilled lab personnel. The electrochemical immunosensor is a useful tool for determining toluene exposure in industrial and environmental settings or substance abuse, such as glue-sniffing, that overcomes these disadvantages and allows analysis of chemical compounds qualitatively and quantitatively without the need for specialized skills [8-11].

Electrochemical immunoassays have many advantages over conventional immunoassays, such as simple instrumentation, relatively low cost, miniaturization, portability, disposability, and full automation, and have therefore attracted keen interest from researchers [12-15]. Particularly interesting are electrochemical immunoassays that use metals or metal nanoparticles and have the advantages of high sensitivity and rapid electron transport reaction due to the increased electrode surface area and conductivity. Among different metals used for electrodes, Ni is less expensive than $\mathrm{Pt}$ or $\mathrm{Au}$ and is easier to obtain. In addition, it has superior electrical oxidation abilities when reacting with oxides. Also, Ni ions can easily bind to an imidazole group and are broadly used in immobilization of substances containing the latter [16-19].

The electrode plays a pivotal role in the electrochemical immunosensor. There are two methods of measurement depending on the use of the electrode: homogenous and heterogeneous. In the easy-to-implement and inexpensive homogeneous method, the antigen-antibody reaction takes place in a solution in which the measurement is consequently performed. The major drawback to this method is its low sensitivity arising from the difficulty of determining whether the reaction between antigens and antibodies actually took place [20-23]. The heterogeneous method requires a more complicated procedure because antigens or antibodies must be first immobilized on the electrode. However, this disadvantage is outweighed by the advantages, such as increased surface area and improved conductivity resulting in enhanced signal integrity. This method leads to improved sensitivity and is widely used in immunological reactions [24,25]. Electrochemical immunoassays are often used in the measurement of blood or urine samples that contain interfering substances such as ascorbic acid, uric acid, ammonia, and urea [26]. It is usually very difficult to distinguish the signal of the target substance from the signals of the interfering substances if the latter are detected during the 
measurement. In order to produce a highly selective electrochemical immunosensor, electrode surface treatment is necessary to prevent the reaction of the interfering substances with the electrode. One of the common methods is to block the electron transfer signals of the interfering substances using organic films. The problem with this method is that the application of the organic films to the electrode leads to a decrease of the signal of the target substance. Therefore, selective signal transmission methods using metal or metal nanoparticles are generally preferred [27,28].

Figure 1. Schematic representation of the fabricating SPCEs/Organic film/Ni/Fe-HA for heterogeneous electrochemical immunoassay.

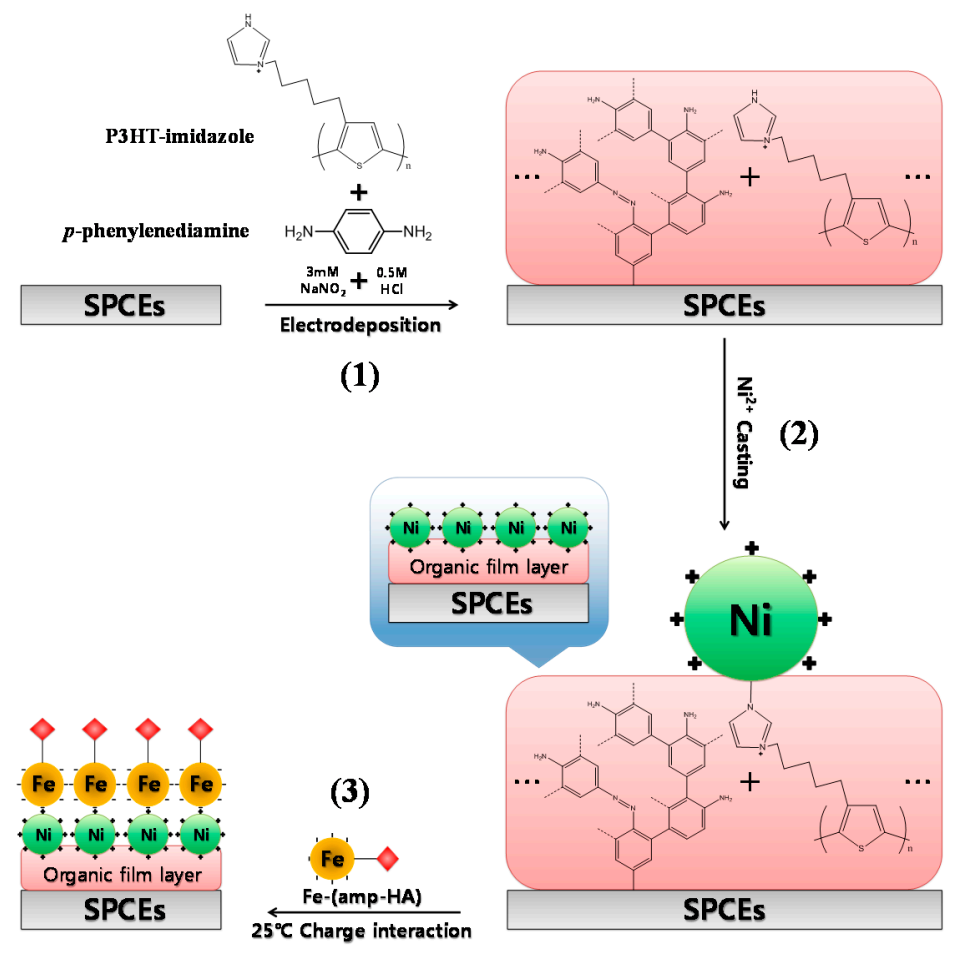

Compared to our previous papers, the benefits of the present paper include (1) the easy immobilization of $\mathrm{Ni}$ ions onto the electrode; (2) the prompt synthesis of ferrate antigen; (3) less interference due to the electrostatic interaction between $\mathrm{Ni}(\mathrm{II})$ and ferrate; and (4) a relatively low cost [29-31]. In this study, we used electrochemical techniques to form organic films containing imidazole rings on the electrodes (Figure 1(1)). Taking advantage of the high affinity between imidazole rings and $\mathrm{Ni}$ ions, we succeeded in electrodepositing $\mathrm{Ni}$ ions (+ charge) on the organic films (Figure 1(2)). Similar to other metal catalysts, Ni ions increased the surface area exhibiting superior electron transfer performance and thus canceling out the signal reduction induced by the inhibition of electron transfer by the organic films. In order to immobilize antigens on $\mathrm{Ni}$ ions ( + charge), we synthesized a Fe-HA complex containing Fe as an electron transfer mediator and HA as an antigen. As shown in Figure 1(3), antigens were finally immobilized onto the electrodes through the charge interaction between $\mathrm{Ni}$ ions ( + charge) and Fe-HA ( - charge), thus minimizing the influence of other interfering substances because only the signal from the HA-tagged Fe complex could be measured. The reaction with anti-HA (HA antibody) was maintained through the Fe-HA-immobilized electrode. Once anti-HA was bound to the electrode through the antigen-antibody reaction, signal intensity was 
reduced due to the Fe-HA's electron transfer inhibition. Based on this phenomenon, we fixed the anti-HA concentration, varied the HA concentration and observed the competition reaction between HA and Fe-HA immobilized on the electrode surface. As a result, we confirmed that an increase in HA concentration led to a signal increase because anti-HA could no longer bind to the electrode surface. This discovery led to the development of the electrochemical immunosensor capable of quantitatively analyzing HA.

\section{Experimental Section}

\subsection{Reagents}

A carbon electrode was screen-printed on an overhead projector (OHP) film (Electrodag 423SS, Acheson, Port Huron, MI, USA) using a screen printing machine (BS-860AP, Bando, Seoul, Korea). Monoclonal anti-HA (HA antibody) was kindly donated by HBI (Seoul, Korea). 4-aminomethylpyridine, HA, p-phenylenediamine, sodium nitrite, nickel chloride( II) hexahydrate, buffering salts, and other chemicals were purchased from Sigma-Aldrich Co. (Milwaukee, WI, USA). Ammonium disodium pentacyanoamminferrate dehydrate was purchased from Fluka. Phosphate-buffered saline (PBS, $4.3 \mathrm{mM} \mathrm{NaH}_{2} \mathrm{PO}_{4}, 15.1 \mathrm{mM} \mathrm{Na}_{2} \mathrm{HPO}_{4}$, and $140 \mathrm{mM} \mathrm{NaCl}$ ) and all other solutions were prepared using deionized Milli-Q water (Millipore, Bedford, MA, USA). All chemicals used were of analytical grade.

Poly\{3-[6-(1-methylimidazolium-3-yl)alkyl]thiophene-2,5-diyl bromide $\} \quad$ (P3HT-imidazole), a conductive polymer, was synthesized following a procedure described in previous papers $[32,33]$.

\subsection{Preparation of $\left[\mathrm{Fe}(\mathrm{CN})_{5}(\mathrm{amp}-\mathrm{HA})\right]^{3-/ 2-}(\mathrm{Fe}-\mathrm{HA})$}

The complex of $[\mathrm{Fe}(\mathrm{CN}) 5(\mathrm{amp}-\mathrm{HA})]^{3-/ 2-}(\mathrm{Fe}-\mathrm{HA})$ was synthesized as described previously [34]. Fifty milligrams of $\mathrm{Na}_{2}\left[\mathrm{Fe}(\mathrm{CN})_{5} \mathrm{NH}_{3}\right] \cdot 2 \mathrm{H}_{2} \mathrm{O}$ and $44.4 \mathrm{mg}$ of amp-HA were dissolved in $60 \mathrm{~mL}$ of aqueous ethanol solution (v/v: 50/50) and kept at room temperature for $24 \mathrm{~h}$. After filtering, the solution was added to $2.0 \mathrm{~L}$ of diethyl ether with vigorous stirring. The product was precipitated, washed with ethanol and then dried for several hours in a vacuum oven.

Figure 2. Preparation of Fe-conjugated HA antigen $\left[\mathrm{Fe}(\mathrm{CN})_{5}(\operatorname{amp}-\mathrm{HA})\right]^{3-/ 2-}(\mathrm{Fe}-\mathrm{HA})$.

(a)

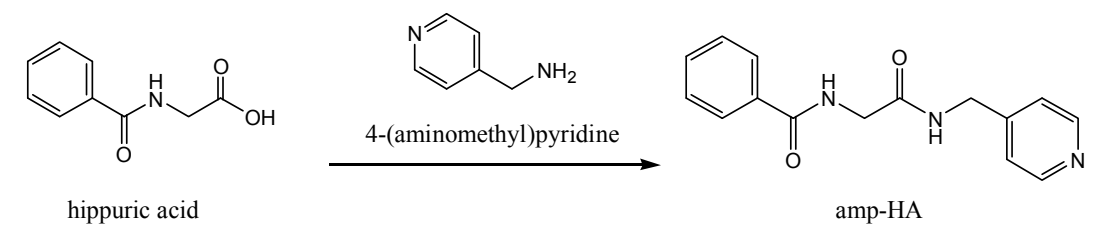

(b)
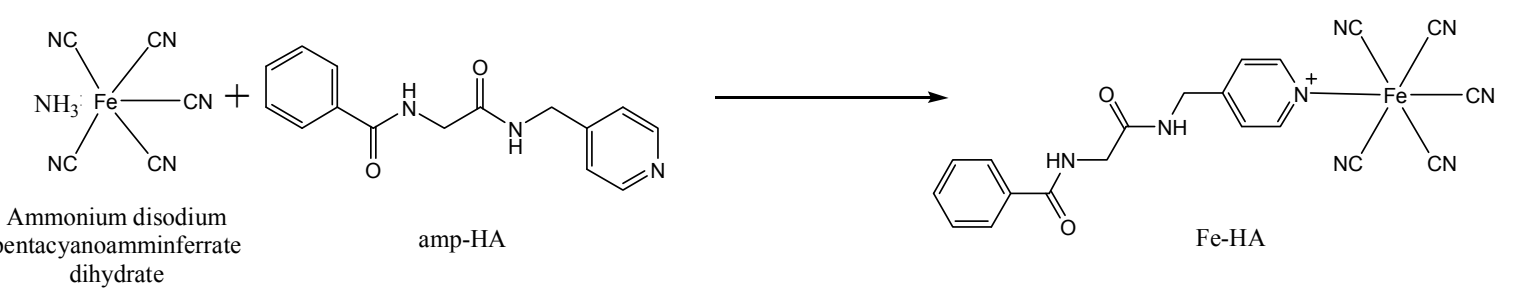
The synthesis of amp-HA (Figure 2a) was confirmed by thin-layer chromatography (TLC) and ${ }^{1} \mathrm{H}$ NMR spectroscopy. The ${ }^{1} \mathrm{H}$ NMR spectrum (400 MHz, DMSO) was as follows: $\delta_{\text {ppm }} 7.45-7.95$ (m, $5 \mathrm{H}$, phenyl), 7.32-8.65 (m, 4H, Py), 3.98-4.25 (t, 4H, $J=7.0 \mathrm{~Hz},-\mathrm{CH}_{2}-\mathrm{CH}_{2}-$ ), 7.8-8.01 (m, 2H, -NH-NH-). The conjugation of Fe-HA (Figure $2 b$ ) was verified by UV-vis and FT-IR spectroscopy.

\subsection{Electrochemical Measurements}

Electrochemical measurements were carried out with a $\mathrm{CH}$ Instruments model 660A electrochemical workstation ( $\mathrm{CH}$ Instrument, Austin, TX, USA), interfaced to a computer. The electrochemical characteristics of Fe-HA were studied using $3.0 \mathrm{~mm}$-diameter screen printed carbon electrodes (SPCEs) as the working electrodes. $\mathrm{An} \mathrm{Ag} / \mathrm{AgCl}$ micro-reference electrode $(3.0 \mathrm{M} \mathrm{KCl}$, Cypress, Lawrence, KS, USA) scrolled with a $0.5 \mathrm{~mm}$ diameter platinum wire counter-electrode was used.

\subsection{Formation of Organic Films Containing Imidazole Rings on SPCEs}

In order to form organic films containing imidazole rings on SPCEs, we prepared a conductive polymer solution by mixing $5 \mathrm{~mL}$ of a $3 \mathrm{mM}$ solution of p-Phenylenediamine $(3.24 \mathrm{mg})$ in $0.5 \mathrm{M} \mathrm{HCl}$ $(10 \mathrm{~mL})$ and $5 \mathrm{~mL}$ of the conductive polymer P3HT-imidazole $(50 \mathrm{mg})$ in Milli-Q water $(10 \mathrm{~mL})$. Sodium nitrate $(2.83 \mathrm{mg})$ was added to the solution and dissolved. After doping $40 \mu \mathrm{L}$ of the resulting solution onto the SPCEs, 5-30 electrodeposition cycles were performed in order to form the organic films on the surface of the SPCEs. In order to bind Ni ions to the imidazole rings in the organic films, $50 \mu \mathrm{L}$ of $100 \mathrm{mM} \mathrm{NiCl} 2$ solution $\left(\mathrm{NiCl}_{2} \cdot 6 \mathrm{H}_{2} \mathrm{O}\right.$ dissolved in Milli-Q water) was doped on the SPCEs formed previously and dried at room temperature for $30 \mathrm{~min}$. The electrodes were then washed with Milli-Q water and dried at room temperature $\left(25^{\circ} \mathrm{C}\right)$. The final step in the electrode production process was the electrodeposition of $40 \mu \mathrm{L}$ of $5 \mathrm{mM}$ Fe-HA onto the surface of the SPCEs containing immobilized $\mathrm{Ni}$ ions, followed by drying at room temperature $\left(25^{\circ} \mathrm{C}\right)$ for $60 \mathrm{~min}$, washing with Milli-Q water, and drying again at room temperature $\left(25^{\circ} \mathrm{C}\right)$. The DPV signal of the SPCEs was tested by measuring the intensity for each scan rate $\left(0.01-0.2 \mathrm{Vs}^{-1}\right)$. The electrolyte used in this measurement was $1 \times \mathrm{PBS}(\mathrm{pH} 7.0$ ) containing $1.0 \mathrm{M} \mathrm{NaCl}$, and the range of the measurement potential was $0.4-2.0 \mathrm{~V}$.

\subsection{Immune Reaction between Fe-HA Immobilized on the Electrode and Anti-HA}

Using the electrostatic interaction method, $40 \mu \mathrm{L}$ of the synthesized Fe-HA was electrodeposited on the electrode with immobilized $\mathrm{Ni}$ ions on it and then washed. The electrode was dried at room temperature and then casted with $40 \mu \mathrm{L}$ of anti-HA of different concentrations $(0-5 \mathrm{mg} / \mathrm{mL})$. The dependence of electrochemical characteristics on the anti-HA concentration was monitored using differential pulse voltammetry (DPV). The results of DPV from 0.1 to $0.8 \mathrm{~V} v s$. $\mathrm{Ag} / \mathrm{AgCl}$ with a pulse amplitude of $0.05 \mathrm{~V}$ and a pulse width of $50 \mathrm{~ms}$ were collected and plotted as the electrochemical immunosensor signal.

\subsection{Competition Reaction between Immobilized Fe-HA and Free HA}

Twenty microliters HA of different concentrations $(0-5 \mathrm{mg} / \mathrm{mL})$ followed by $20.0 \mu \mathrm{L}$ anti-HA at a concentration of $1.0 \mathrm{mg} / \mathrm{mL}$ were casted on the electrode, on which Fe-HA was immobilized. 
The effect of different HA concentrations on electrochemical characteristics was measured by DPV after an initial delay of $30 \mathrm{~s}$ to allow the reaction to take place. The results of DPV from 0.1 to $0.8 \mathrm{~V}$ vs. $\mathrm{Ag} / \mathrm{AgCl}$ with pulse amplitude of $0.05 \mathrm{~V}$ and a pulse width of $50 \mathrm{~ms}$ was collected and plotted as the electrochemical immunosensor signal.

\section{Results and Discussion}

\subsection{Adsorption of Ni Ions to the Organic Films for the Immunosensor}

After forming organic film layers of various thicknesses from p-Phenylenediamine and P3HT-imidazole polymers via electrodeposition cycles and adsorbing Ni ions to each organic film, we added $\mathrm{K}_{3} \mathrm{Fe}(\mathrm{CN})_{6}(5 \mathrm{mM})$ and $1 \times$ PBS $(\mathrm{pH} 7.4), 20 \mu \mathrm{L}$ each, and measured signal intensities to test the electron transfer performance of the electrode. The results revealed that as the number of electrodeposition cycles increased, the bare organic film gradually lost signal intensity (Figure 3a), whereas the Ni-immobilized organic film had a steady signal intensity up to 10 cycles, beyond which the signal intensity dropped abruptly (Figures $3 \mathrm{~b}$ and 4). Covering electrodes with organic films is a superior technology for their protection, which allows elimination of the signals of the interfering substances present in blood or urine. However, the presence of an organic film adversely affects the electron transfer process and thus inhibits the generation of electrochemical signals [35]. While metal nanoparticles are frequently used in order to overcome this drawback, in this study, we developed a method for increasing the electron transfer reaction by binding Ni ions in lieu of metal nanoparticles, taking advantage of the catalytic properties of Ni ions. However, the signal intensity could no longer be maintained after 10 cycles, when the thickness of the organic film layer exceeds $20 \AA$, whereby $\mathrm{Ni}$ ions can no longer contribute to the electron transfer [36]. Given the fact that the signal recovery performance of $\mathrm{Ni}$ reaches its limit at a certain thickness of the organic film, we chose 10 cycles as an optimal condition of adsorption of $\mathrm{Ni}$ ions to the organic film.

Figure 3. Cyclic voltammograms for (a) SPCEs/Organic film and (b) SPCEs/Organic film/Ni surface recorded in phosphate buffer solution containing $2 \mathrm{mM} \mathrm{K} 3 \mathrm{Fe}(\mathrm{CN})_{6}$. Cyclic voltammetry was conducted at a scan rate of $100 \mathrm{mVs}^{-1}$. Inset: Anode currents at $0.375 \mathrm{~V}$ versus $\mathrm{Ag} / \mathrm{AgCl}$ as a function of the number of cycles, ranging between five and 30 .

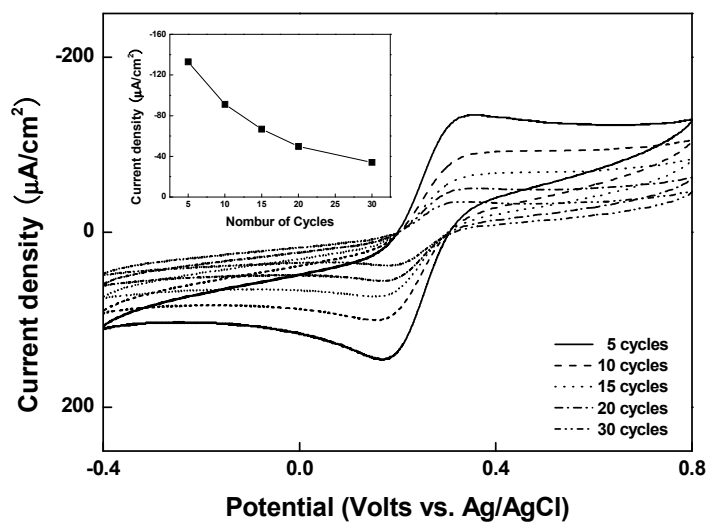

(a)

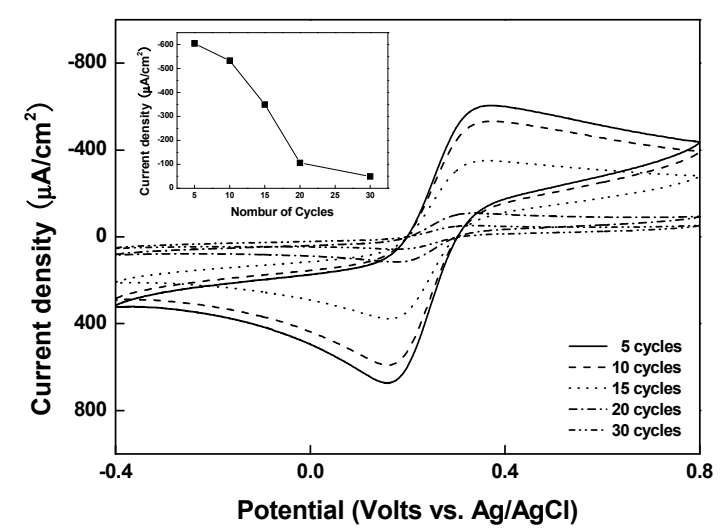

(b) 
Figure 4. Cyclic voltammograms for: (a) SPCEs/Organic film and (b) SPCEs/Organic film/Ni surfaces, recorded in phosphate buffer solution containing $2 \mathrm{mM} \mathrm{K} 3 \mathrm{Fe}(\mathrm{CN})_{6}$. Cyclic voltammetry was conducted at a scan rate of $100 \mathrm{mVs}^{-1}$, and the voltammograms are compared to the bare SPCEs, dashed line.
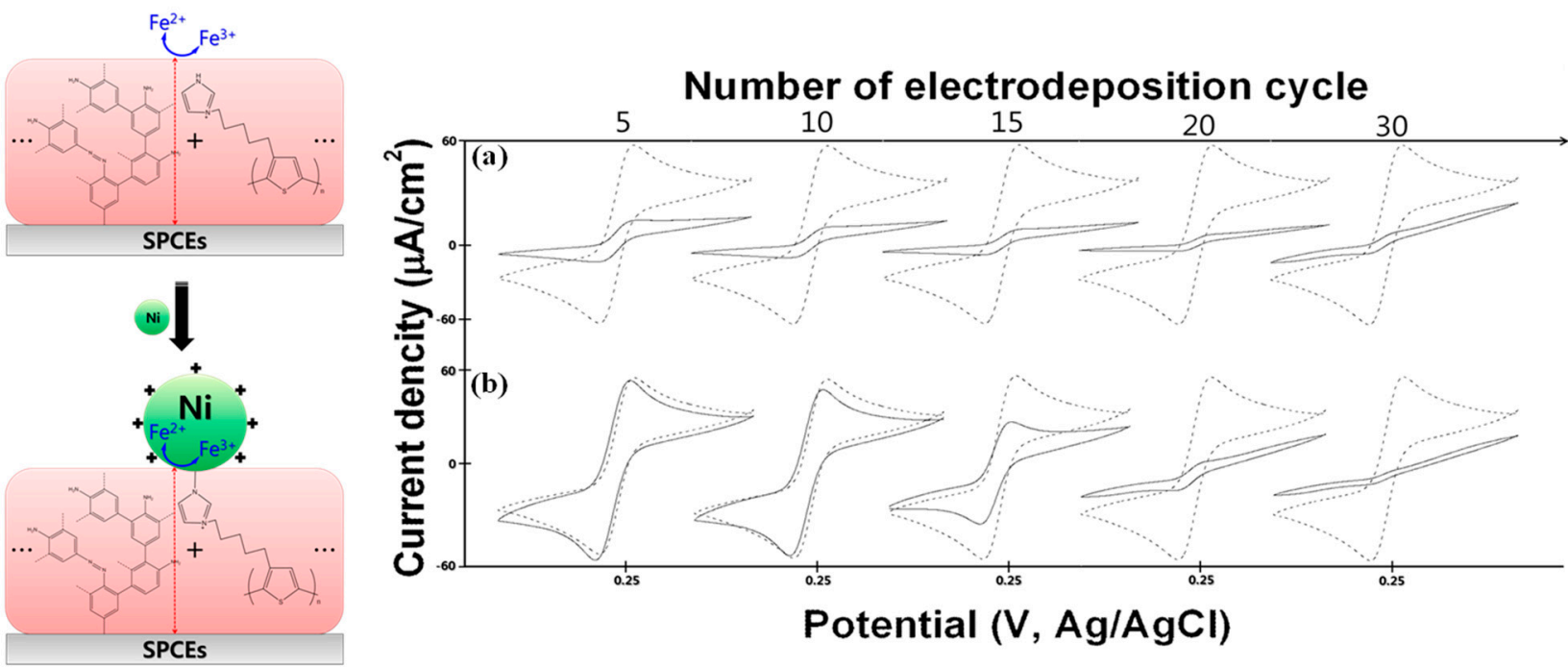

Figure 5. Differential pulse voltammograms of the SPCEs/Organic film/ $\mathrm{Ni} / \mathrm{Fe}-\mathrm{HA}$ with variable anti-HA $\left(0 \sim 5 \mathrm{mg} \mathrm{mL}^{-1}\right)$. Inset shows the calibration curve of the cathodic DPV peak current of SPCEs/Organic film/Ni/Fe-HA at $0.45 \mathrm{~V}$ versus $\mathrm{Ag} / \mathrm{AgCl}$ as a function of the anti-HA concentrations.

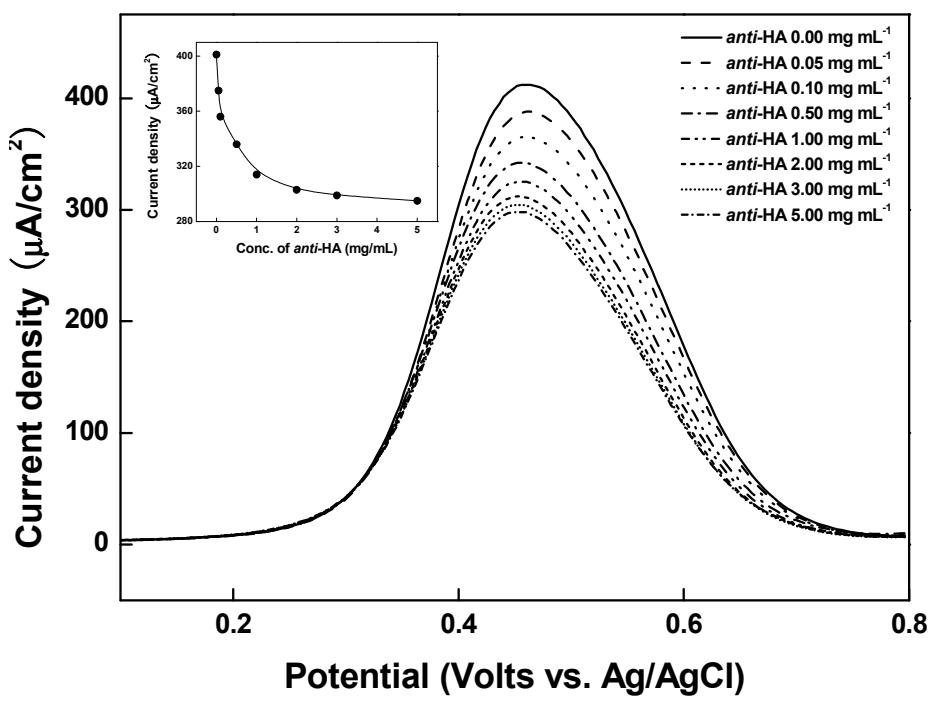

\subsection{Electrochemical Measurements of the Immunosensor}

\subsubsection{Immune Reaction between Immobilized Fe-HA and Anti-HA}

Taking characteristic of the high selectivity and the large molecular mass $(\sim 150,000 \mathrm{Da})$ of anti-HA, as well as its ability to inhibit the electron transfer of the HA-tagged Fe complex (Fe-HA), we cast anti-HA $(40 \mu \mathrm{L})$ of different concentrations $(0-5 \mathrm{mg} / \mathrm{mL})$ and measured the DPV on 
SPCEs/Organic film/Ni/Fe-HA. The applied potential ranged from 0.1 to $0.8 \mathrm{~V}$ and the scan rate was $50 \mathrm{mV} / \mathrm{sec}$. The curve in the inset graph in Figure 5 shows the dependency of the cathodic peak current fixed at $0.45 \mathrm{~V}$ (versus $\mathrm{Ag} / \mathrm{AgCl}$ ) on the anti-HA concentration. When the concentration of anti-HA reaches $1 \mathrm{mg} / \mathrm{mL}$, the cathodic peak current sharply decreases and approaches the saturation state of the threshold current in which anti-HA can no longer bind to Fe-HA. The incubation time of anti-HA with the electrode at this point was $20 \mathrm{~min}$ [37].

Figure 6. Differential pulse voltammograms of the SPCEs/Organic film/Ni/Fe-HA with variable HA $\left(0 \sim 5 \mathrm{mg} \mathrm{mL}^{-1}\right)$. Inset shows the calibration curve of the anodic DPV peak current of SPCEs/Organic film/Ni/Fe-HA at $0.45 \mathrm{~V}$ versus $\mathrm{Ag} / \mathrm{AgCl}$ as a function of the HA concentrations $(\mathrm{N}=6, \mathrm{r}=0.9943)$.

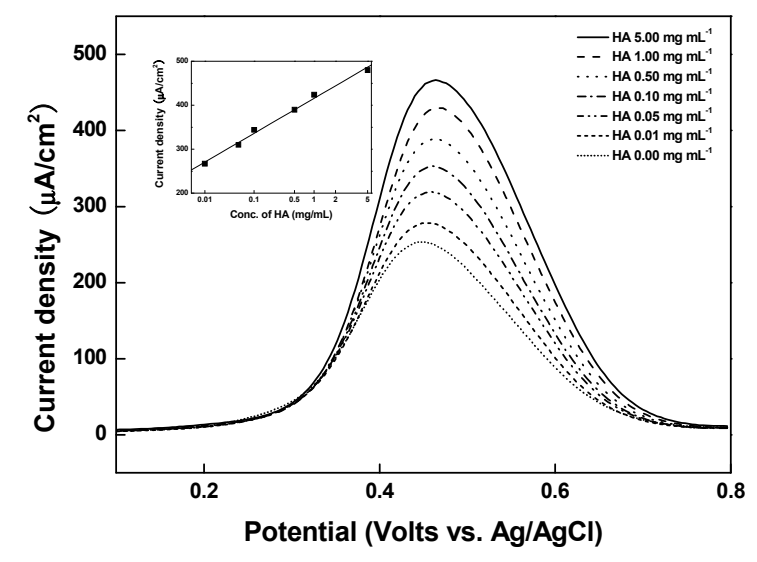

\subsubsection{Competition Reaction of Immobilized Fe-HA with Free HA}

The electrode produced by adsorption of Fe-HA of fixed concentration on SPCEs/Organic film/Ni was casted with $20 \mu \mathrm{L}$ of HA of various concentrations $(0-5 \mathrm{mg} / \mathrm{mL})$ and allowed to react with $20 \mu \mathrm{L}$ of anti-HA (1 mg/mL) for $30 \mathrm{~s}$ and was then checked by DPV. It was verified that, due to the competition reaction between $\mathrm{HA}$ and Fe-HA, an increase in the concentration of HA resulted in an increase in its binding with anti-HA. This, in turn, lead to an increase in the number of free Fe-HA thus yielding high current values owing to a smooth electron transfer at the electrode surface. The curve in the inset graph in Figure 6 represents the correlation between the anodic peak current fixed at $0.45 \mathrm{~V}$ (versus $\mathrm{Ag} / \mathrm{AgCl}$ ) and the concentration of $\mathrm{HA}$. The redox current increased in proportion to the logarithm of the HA concentration of $0.01-5.00 \mathrm{mg} \mathrm{mL}^{-1}$, and the limit of detection (LOD) was $5.0 \mu \mathrm{g} \mathrm{mL}^{-1}(\mathrm{~N}=6, \mathrm{r}=0.9943)$. Considering that the cutoff concentration of urinary HA is $2.0 \mathrm{mg} \mathrm{mL}^{-1}$, the following results indicate the success of electrochemical immunoassay.

\subsubsection{Effects of Ascorbic Acid on the Organic Films}

In order to investigate the potential influence on the electrode of ascorbic acid, which is a common interfering substance in urine, we used cyclic voltammetry to compare the values of the oxidation potential of ascorbic acid in the SPCEs and the same values in SPCEs/Organic film/Ni/Fe-HA (Figure 7). After casting $40 \mu \mathrm{L}$ of $2 \mathrm{mM}$ ascorbic acid on common SPCEs and SPCEs/Organic film $/ \mathrm{Ni} / \mathrm{Fe}-\mathrm{HA}$, we measured the respective electrical characteristics. In the case of common SPCEs, 
the oxidation current value of ascorbic acid increased continuously starting from approximately $0.35 \mathrm{~V}$, and the extremely high signal of ascorbic acid interfered with the Fe-HA signal and actually canceled it out. On the contrary, the ascorbic acid signal in the electrode was negligible compared to the signal of $\mathrm{Fe}-\mathrm{Ha}$, thus verifying that the interfering substances did not affect the electrode. This may be attributed to the extremely limited electron transfer of ascorbic acid in the presence of the organic film, whereas Ni ions of the organic film present on the surface of the electrode selectively immobilize Fe-HA and display the redox signal of Fe-HA.

Figure 7. Cyclic voltammogram of the SPCEs/Organic film/Ni/Fe-HA in $2 \mathrm{mM}$ ascorbic acid solution at scan rate of $0.10 \mathrm{~V} \mathrm{~s}^{-1}$.

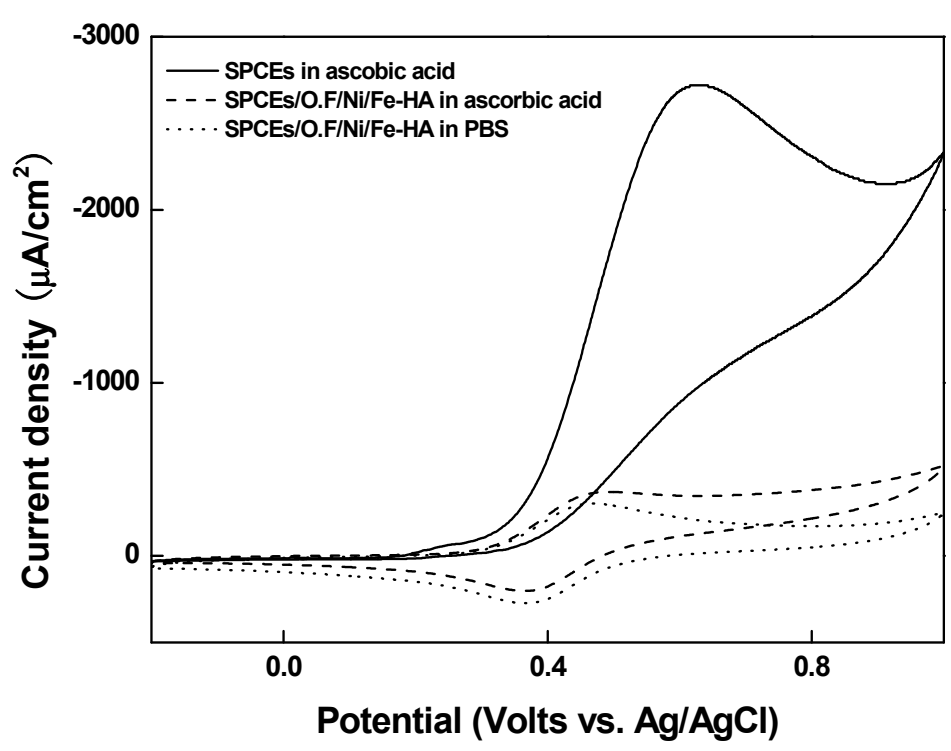

\section{Conclusions}

In this study, we formed organic film layers containing imidazole rings on common SPCEs using the electrodeposition method and demonstrated their applicability as electrochemical immunoassay electrodes. Subsequently, exploiting the high affinity between imidazole rings and $\mathrm{Ni}$ ions, we immobilized $\mathrm{Ni}$ ions on the organic film layers and observed the signal amplification due to the catalytic effects of Ni ions. Additionally, the complex of HA with Fe (an electron transfer mediator) was immobilized on this electrode by means of electrostatic interactions and the latter was applied as an electrochemical immunosensor for toluene detection. By applying the heterogeneous approach to measure the competition between $\mathrm{HA}$ and Fe-HA, it was revealed that the electric current values increased in response to an increase in the concentration of HA. Electrodes using organic films can be produced easily and rapidly and applied to a variety of electrochemical immunoassays. They could, therefore, be useful for point-of-care (POC) diagnosis in healthcare.

\section{Acknowledgments}

The present research was supported by the research fund of Dankook University in 2013. 


\section{Author Contributions}

Y-B Choi and N-H Kim fabricated the modified electrodes and performed the experiments. S-H Kim synthesized the organic films. G-S Tae synthesized the monoclonal HA-antibody conjugates. Y-B Choi and H-H Kim wrote and received the manuscript. All authors discussed the results and commented on the manuscript.

\section{Conflicts of Interest}

The authors declare no conflict of interest.

\section{References}

1. Boor, J.W.; Hurtig, H.I. Persistent cerebellar ataxia after exposure to toluene. Ann. Neurol. 1977, 2, 440.

2. Rosenberg, N.L.; Spitz, M.C.; Filley, C.M.; Davis, K.A.; Schaumburg, H.H. Central nervous system effects of chronic toluene abuse-Clinical, brainstem evoked response and magnetic resonance imaging studies. Neurotoxicol. Teratol. 1988, 10, 489-195.

3. Feldman, R.G.; Ratner, M.H.; Ptak, T. Chronic Toxic Encephalopathy in a Painter Exposed to Mixed Solvents. Environ. Health Perspect. 1999, 107, 417-422.

4. Park, H.M.; Lee, S.H.; Chung, H.; Kwon, O.H.; Yoo, K.Y.; Kim, H.H.; Heo, S.C.; Park, J.S.; Tae, G.S. Immunochromatographic Analysis of Hippuric Acid in Urine. J. Anal. Toxicol. 2007, 31, 347-353.

5. Kongtip, P.; Vararussami, J.; Pruktharathikul, V. Modified method for determination of hippuric acid and methylhippuric acid in urine by gas chromatography. J. Chromatogr. B Biomed. Sci. Appl. 2001, 751, 199-203.

6. Tomokuni, K.; Ogata, M. Direct Colorimetric Determination of Hippuric Acid in Urine. Clin. Chem. 1972, 18, 349-351.

7. Sakai, T.; Niinuma, Y.; Yanagihara, S.; Ushio, K. Liquid-chromatographic separation and determination of coproporphyrins I and III in urine. J. Chromatogr. 1983, 276, 182.

8. Wang, J.; Ibanez, A.; Chatrathi, M.P.; Escarpa, A. Electrochemical enzyme Immunoassays on Microchip Platforms. Anal. Chem. 2001, 73, 5323-5327.

9. Duan, C.; Meyerhoff, M.E. Separation-Free Sandwich Enzyme Immunoassays Using Microporous Gold Electrodes and Self-Assembled Monolayer/Immobilized Capture Antibodies. Anal. Chem. 1994, 66, 1369-1377.

10. Moore, T.J.; Joseph, M.J.; Allen, B.W.; Coury, L.A., Jr. Enzymatically Amplified Voltammetric Sensor for Microliter Sample Volumes of Salicylate. Anal. Chem. 1995, 67, 1896-1902.

11. Wang, J.; Tian, B.; Roggers, K.R. Thick-Film Electrochemical Immunosensor Based on Stripping Potentiometric Detection of a Metal Ion Label. Anal. Chem. 1998, 70, 1682-1685.

12. Heineman, W.R.; Halsall, H.B. Strategies for Electrochemical Immunoassay. Anal. Chem. 1985, 57, 1321A-1331A.

13. Warsinke, A.; Benkert, A.; Scheller, F.W. Electrochemical Immunoassay. Anal. Chem. 2000, 366, 622-634. 
14. Ronkainen-Matsuno, N.J.; Thomas, J.H.; Halsall, H.B.; Heineman, W.R. Electrochemical Immunoassay moving into the fast lane. TrAC-Anal. Chem. 2002, 21, 213-225.

15. Wijayawardhana, C.A.; Halsall, H.B.; Heineman, W.R. Milestones of Electrochemical Immunoassay at Cincinnati. In Electroanalytical Methods of Biological Meterials; Anna, B.T., James, A.C., Eds.; Marcel Dekker Inc.: New York, NY, USA, 2002; pp. 87-108.

16. Mu, Y.; Jia, D.; He, Y.; Miao, Y.; Wu, H.L. Nano nickel oxide modified non-enzymatic glucose sensors with enhanced sensitivity through an electrochemical process strategy at high potential. Biosens. Bioelectron. 2011, 26, 2948-2952.

17. Shamsipur, M.; Najafi, M.; Hosseini, M.R.M. Highly improved electrooxidation of glucose at a nickel(II) oxide/multi-walled carbon nanotube modified glassy carbon electrode. Bioelectrochemistry 2010, 77, 120-124.

18. Sigel, H.; Saha, A.; Saha, N.; Carloni, P.; Kapinos, L.E.; Griesser, R. Evaluation of intramolecular equilibria in complexes formed between substituted imidazole ligands and nickel(II), copper(II) or zinc(II). J. Inorg. Biochem. 2000, 78, 129-137.

19. Bauman, J.E.; Wang, J.C. Imidazole Complexes of Nikel(II), Copper(II), Zinc(II), and Silver(II). Inorg. Chem. 1964, 3, 368-373.

20. Carlo, M.D.; Lionti, I.; Taccini, M.; Cagnini, A.; Mascini, M. Disposable screen-printed electrodes for the immunochemical detection of polychlorinated biphenyls. Anal. Chim. Acta 1997, 342, 189-197.

21. Ho, W.O.; McNeil, C.J. Amperometric detection of alkaline phosphatase activity at a horseradish peroxidase enzyme electrode based on activated carbon: Potential application to electrochemical immunoassay. Biosens. Bioelectron. 1995, 10, 683-691.

22. Sanchez, C.F.; Gonzalez-Garcia, M.B.; Costa-Garcia, A. AC voltammetric acarbon paste-based enzyme immunosensors. Biosens. Bioelectron. 2000, 14, 917-924.

23. Tang, H.T.; Lunte, C.E.; Halsall, H.B.; William, R.; Heineman, W. P-aminophenyl phosphate: An improved susbstrate for electrochemical enzyme immunoassay. Anal. Chim. Acta 1988, 214, 187-195.

24. Fowler, J.M.; Wong, D.K.Y.; Halsall, H.B.; Heineman, W.R. Recent Developments in Electrochemical Immunoassay and Immunosensors. In Electrochemical Sensors, Biosensors and their Biomedical Applications; Zhang, X., Ju, H., Wang, J., Eds.; Elsevier: Oxford, UK, 2008; pp. 115-143.

25. Yakovleva, J.; Emneus, J. Electrochemical Immunoassays. In Bioelectrochemistry: Fundamentals, Experimental Techniques and Application; Bartlett, P.N., Ed.; Wiley: Chichester, UK, 2008; pp. $377-410$.

26. Wang, J.; Llu, J.; Chen, L.; Lu, F. Highly Selective Membrane-Free, Mediator-Free Glucose Biosensor. Anal. Chem. 1994, 66, 3600-3603.

27. Shein, J.B.; Lai, L.M.H.; Eggers, P.K.; Paddon-Row, M.N.; Gooding, J.J. Formation of Efficient Electron Transfer Pathways by Adsorbing Gold Nanoparticles to Self-Assembled Monolayer Modified Electrodes. Langmuir 2009, 25, 11121-11128.

28. Chazalviel, J.N.; Allongue, P. On the Origin of the Efficient Nanopartical Mediated Electron Transfer across a Self-Assembled Monolayer. J. Am. Chem. Soc. 2011, 133, 762-764. 
29. Choi, Y.B.; Tae, G.S. Simple Electrochemical Immunoassay for the Detection of Hippuric Acid on the Screen-Printed Carbon electrode Modified Gold Nanoparticles. J. Korean Electrochem. Soc. 2011, 14, 44-49.

30. Choi, Y.B.; Kim, H.H. Electrochemical Method for Detecting Hippuric Acid Using Osmium-antigen Conjugate on the Gold Nanoparticles Modified Screen-Printed Carbon Electrodes. J. Electrochem. Sci. Technol. 2011, 2, 57-61.

31. Choi, Y.B.; Jeon, W.Y.; Kim, H.H. Electrochemical Immunoassay for Detecting Hippuric Acid Based on the Interaction of Osmium-Antigen Conjugate Films with Antibody on Screen Printed Carbon Electrodes. Bull. Korean Chem. Soc. 2012, 33, 1485-1490.

32. Clement, S.; Tizit, A.; Desbief, S.; Mehdi, A.; Winter, J.D.; Gerbaux, P.; Lazzaroni, R.; Boury, B. Synthesis and characterisation of $\pi$-conjugated polymer/silica hybrids containing regioregular ionic polythiophenes. J. Mater. Chem. 2011, 21, 2733-2739.

33. Kim, S.H. Utilization of Zinc Dust for a Core Monomer 2-Bromo-3-hexylthien-5-ylzinc Bromide: Its Synthesis and Application for the Preparation of Regioregular Poly(3-hexylthiophene). Int. J. Polym. Sci. 2014, 2014, 5.

34. Choi, Y.B.; Jeon, W.Y.; Kim, H.H. The Coordination of Pyridyl-N to Pentacyanoferrate for the Electrochemical Detecting Small Organic Molecules. Bull. Korean Chem. Soc. 2013, 34, 595-599.

35. Barfidokht, A.; Ciampi, S.; Luais, E.; Darwish, N.; Gooding, J.J. The Influence of Organic-Film Morphology on the Efficient Electron Transfer at Passivated Polymer-Modified Electrodes to which Nanoparticles are Attached. ChemPhysChem 2013, 14, 2190-2197.

36. Barfidokht, A.; Ciampi, S.; Luais, E.; Darwish, N.; Gooding, J.J. Distance-Dependent Electron Transfer at Passivated Electrodes Decorated by Gold Nanoparticles. Anal. Chem. 2013, 85, 1073-1080.

37. Jeon, W.Y.; Choi, Y.B.; Kim, H.H. Homogeneous Electrochemical Detection of Hippuric Acid in Urine Based on the Osmium-Antigen Conjugate. ChemPhysChem 2013, 14, 2331-2337.

(C) 2014 by the authors; licensee MDPI, Basel, Switzerland. This article is an open access article distributed under the terms and conditions of the Creative Commons Attribution license (http://creativecommons.org/licenses/by/4.0/). 